Revue

Revue de l'histoire des religions

de Ihistoire des religions

$1 \mid 2020$

Varia

Pamela NouRRIGEON, De la translation à la création : les images dans les manuscrits du Rational des divins offices Paris, Cerf (« Patrimoines »), 2018

Alain Rauwel

\title{
CpenEdition
}

Journals

Édition électronique

URL : https://journals.openedition.org/rhr/10366

DOI : 10.4000/rhr.10366

ISSN : 2105-2573

Éditeur

Armand Colin

Édition imprimée

Date de publication : 1 mars 2020

Pagination : 141-142

ISBN : 978-2-200-93291-6

ISSN : 0035-1423

Référence électronique

Alain Rauwel, «Pamela NourRigeon, De la translation à la création : les images dans les manuscrits du Rational des divins offices ", Revue de l'histoire des religions [En ligne], 1 | 2020, mis en ligne le 01 janvier 2021, consulté le 05 janvier 2023. URL : http://journals.openedition.org/rhr/10366 ; DOI : https:// doi.org/10.4000/rhr.10366

Ce document a été généré automatiquement le 5 janvier 2023.

Tous droits réservés 


\section{Pamela NoURRIGEON, De la translation à la création : les images dans les manuscrits du Rational des divins offices}

Paris, Cerf (« Patrimoines »), 2018

Alain Rauwel

\section{RÉFÉRENCE}

Pamela NOURRIGEON, De la translation à la création : les images dans les manuscrits du Rational des divins offices, Paris, Cerf (« Patrimoines »), 2018, 315 p., $32 €$, ISBN 978-2-204-12967-1.

1 La représentation figurée des actions liturgiques est un domaine longtemps délaissé par une érudition presque exclusivement attentive aux textes. Toute analyse détaillée d'un corpus de ce type est donc bienvenue, et il est difficile d'en trouver un meilleur que celui formé par les exemplaires illustrés du Rationale divinorum officiorum de Guillaume Durand dans la traduction française de Jean Golein pour Charles V. Une dizaine de manuscrits s'offre à l'étude, dont - situation très exceptionnelle - un exemplar (Arsenal 2002) portant de nombreuses indications écrites à l'usage du copiste, qui éclairent le processus de conception de l'image. Pamela Nourrigeon a eu l'heureuse idée de consacrer sa thèse à l'examen systématique de cette tradition iconographique.

2 Le livre qui en résulte déroute quelque peu le lecteur. La cause première est entièrement de la responsabilité de l'éditeur. Imagine-t-on une recherche centrée sur l'image et publiée avec une illustration aussi chiche que peu utilisable ? Il semble qu'au Cerf on l'imagine sans mal : $3,5 \times 7 \mathrm{~cm}$ pour la reproduction du célèbre et fascinant parallèle des trois cultes! On s'use les yeux pour mal voir, et donc mal profiter du raisonnement de P. Nourrigeon. Mais une seconde cause accroît la perplexité, et c'est le caractère éclaté du plan. La première partie de l'ouvrage est la seule à poser 
directement la question de la liturgie en images. Les quatre chapitres suivants examinent chacun une problématique très spécifique, l'unité de l'ensemble peinant à apparaître. De nombreuses pages sont dévolues à l'image de la monarchie française, dans un traité mis en français pour le roi et dans lequel, comme chacun sait, le traducteur a introduit un prolixe Traité du sacre entièrement de son cru. Les remarques faites à ce sujet sont justes et fort bien informées, mais on ne peut se déprendre de l'impression qu'elles ne sont pas vraiment nouvelles, le sacre et son symbolisme ayant suscité depuis des décennies les réflexions d'innombrables chercheurs. L'occasion était donnée de s'attaquer à de l'inédit, était-ce la meilleure idée de le rabattre sur du connu, et même du bien connu ? Plutôt que de revenir à l'oriflamme royale, ne vaudrait-il pas mieux s'interroger sur le magnifique vexillum présent, par exemple, dans l'image de la consécration de l'église ? Si la liturgie ne sert qu'à fournir des notes de bas de page à la plus classique des histoires politiques, à quoi bon s'y consacrer, se demanderont certains.

On en dirait autant, mutatis mutandis, du chapitre voué à la représentation des saints. Celui qui porte sur «le Rational comme écrin pour la valorisation de l'ordre carme » suscite les plus vives attentes, dans le grand désert des études historiques sur les Frères du Mont Carmel au Moyen Âge. Il n'est pas certain qu'il y réponde. De longues considérations sur le thème iconographique de la montagne ou de l'arbre n'aboutissent que très indirectement chez les fils d'Élie, a fortiori les développements sur le miroir, qui négligent un peu trop le fait que c'est précisément l'exemplaire royal qui ne comporte pas la figuration de ce speculum qui n'est pas nécessairement regis et pour l'explication duquel le recours à 1 Co 13 suffit largement. Reste le problème fascinant de l'iconographie du paganisme et du judaïsme, soulevé notamment par le très bel exemplaire de Beaune, naguère examiné par Fabienne Joubert. L'enluminure des trois cultes (celui des idoles, celui du Temple, celui de Jésus-Christ) est un extraordinaire exemple de "religion comparée par l'image » en plein $\mathrm{XV}^{\mathrm{e}}$ siècle. P. Nourrigeon lui consacre un intéressant chapitre.

4 Reste que Guillaume Durand est le grand exégète liturique du Moyen Âge et que c'est la possibilité même d'un "traité visuel sur la liturgie» qu'interroge le décor des manuscrits du Rational (auquel il vaut mieux ne pas chercher à accéder par la vieille traduction de Barthélemy, souvent discutable). P. Nourrigeon, qui est ici au cœur de son sujet, a de bonnes pages, par exemple, sur les ornements sacerdotaux comme armes dans le combat contre les vices, ce qui est, de fait, un thème majeur de la spiritualité sacerdotale médiévale. À d'autres moments, la complexité et la technicité de la matière font voir leurs effets. L'élévation n'est certes pas une « nouvelle pratique introduite par les fidèles eux-mêmes ", pas plus que les courtines ou rideaux ne ferment "l'ensemble du chœur liturgique ». La scène souvent reproduite d'un prêtre bénissant un cimetière ne peut pas représenter la dévolution initiale de cet espace aux morts, à l'Église et à Dieu, puisque c'est précisément un clerc du second ordre qui agit et non le pontife, seul qualifié pour les opérations de consécration et de dédicace.

5 Au bout du compte, la juste interprétation des magnifiques manuscrits sur lesquels a travaillé $P$. Nourrigeon dépend d'une détermination fine du public pour lequel ils ont été décorés. Dans plusieurs cas, il est connu : princes et grands nobles. Dans d'autre cas, comme pour le manuscrit de Beaune, on est réduit aux conjectures. Les destinataires ne sont pas, en tout cas, les principaux intéressés par le contenu du texte, à savoir les prélats, qui lisaient Durand en latin. Mais alors, comme le demande très justement $\mathrm{P}$. 
Nourrigeon, comment expliquer l'omniprésence des figures d'évêques dans des manuscrits qui ne leur étaient pas destinés ? Comme le montre bien le livre, c'est la logique de translation qui gouverne toute la démarche : traduire en langue vernaculaire, et du même mouvement inventer une sémiotique iconographique du rite (plutôt qu'une "théologisation des rites à travers l'image»), dont la postérité mériterait d'être examinée sur la longue durée.

\section{AUTEURS}

\section{ALAIN RAUWEL}

Université de Bourgogne. 